Saudi Journal of Medical and Pharmaceutical Sciences

Abbreviated Key Title: Saudi J Med Pharm Sci

ISSN 2413-4929 (Print) |ISSN 2413-4910 (Online)

Scholars Middle East Publishers, Dubai, United Arab Emirates

Journal homepage: http://scholarsmepub.com/sjmps/

Original Research Article

\title{
Diurnal Variation of Peak Expiratory Flow Rate in Healthy South Indian Females
} \author{
Higher Education \& Research (DU) \\ ${ }^{2}$ Post Graduate, Department of Respiratory Medicine, SRMC \& RI, SRIHER (DU) \\ ${ }^{3}$ Associate Professor, Department of Respiratory Medicine, SRMC \& RI, SRIHER (DU) \\ ${ }^{4}$ Assistant Professor, Department of Resipratory Medicine, SRMC \& RI, SRIHER (DU) \\ ${ }^{5}$ Respiratory therapist, SRMC \& RI, SRIHER (DU) \\ ${ }^{6}$ Head of the Department, Respiratory Medicine, SRMC \& RI, SRIHER (DU)
}

Abdul Majeed Arshad ${ }^{1 *}$, B.Divya ${ }^{2}$, Irfan Ismail Ayub ${ }^{3}$, Sindhura Koganti ${ }^{4}$, Kiruba Harini ${ }^{5}$, Chandrasekar $C^{6}$

${ }^{1}$ Assistant Professor, Department of Respiratory Medicine, Sri Ramachandra Medical College \& Research Institute, Sri Ramachandra Institute of

DOI: $10.36348 /$ sjmps.2019.v05i12.020

| Received: 20.11.2019 | Accepted: 27.11.2019 | Published: 30.12.2019

*Corresponding author: Abdul Majeed Arshad

\section{Abstract}

Background: Peak expiratory flow rate (PEFR) reflects the strength and condition of respiratory muscles and the degree of airflow limitation in large airways. PEFR is recorded in Mini Wrights Peak Flow Meter and it is commonly used for screening the individuals who are asthmatics. PEFR shows hour to hour variation that follows a specific pattern in asthmatics and healthy individuals. Circardian oscillations in the sympathetic activity may have impact on the airway smooth muscles. Materials and Methods: Peak expiratory flow rate was recorded in 60 young healthy females in the age group of 18-25years in Sri Ramachandra Institue of Higher Education and Reasearch. Mini Wright's peak flow meter was used to measure the peak expiratory flow rate. PEFR was recorded at 6-7am, 9-10am, 1-2pm, 5-6pm, 10-11pm in a single day. Results: Our results showed PEFR values were low in the morning, followed by progressive rise peaking in the afternoon and evening and a small fall at night time. Highest PEFR is seen around afternoon. Conclusion: Comparing the PEFR readings there ia diurnal variation there is a diurnal variation in healthy young females showing a overall dip in the morning PEFR at 6 A.M, peaking in the evening PEFR at 6P.M, eventually decrease in night PEFR at 10P.M. But there is no significant in the afternoon (2P.M) and night (10.P.M).

Keywords: Peak expiratory flow rate, Diurnal variation, Healthy young females.

Copyright @ 2019: This is an open-access article distributed under the terms of the Creative Commons Attribution license which permits unrestricted use, distribution, and reproduction in any medium for non-commercial use (NonCommercial, or CC-BY-NC) provided the original author and source are credited.

\section{INTRODUCTION}

The Peak Expiratory Flow Rate (PEFR) is defined as the maximum or peak flow rate that is attained during a forceful expiratory effort after taking a deep inspiration. Its expressed in litres per minute (L/min), it reflects the state of proximal airway caliber and is an effective measure of effort dependent airflow. Peak expiratory flow rate is the maximum expiratory flow rate sustained by a subject for at least 10 milliseconds expressed in Litre per minute [1]. Peak expiratory flow rate had been used as a measurement of ventilator capacity for long mainly because of the ease in using it for maximum voluntary ventilation (MVV) [2].

The basis of most of the various single breath methods is the same, volume of air expired is measured against time by means of a spirometer with either a recording drum or a timing device. All the methods however have some amount of disadvantage that is, the procedure may be cumbersome or they may require electric supply, so the use of a peak expiratory flow rate or maximum expiratory flow rate as a measure of ventilatory capacity measurement has made things simple. Wright and McKerrow described the term peak flow meter, since that time the instrument had been widely used and found to be reliable. The Wright peak flow meter depends upon the rotation of a vane attached to a spiral spring. Movement of the vane uncovers an annular orifice and the point at which pressure behind the vane balances the force of the spring depends upon the flow rate [3]. The standard Wright peak flow meter ranges from 50 to 1000 litres per minute and weighs 900 grams, later various portable smaller and cheaper instruments suitable for domiciliary practice have been developed. The mini wright peak flow meter is simpler version of wright peak flow meter and is now used world wide [4]. Measurements with this instrument correlate with peak expiratory flow rate measurement 
from the larger wright peak flow meter. The instrument is a light plastic cylinder measuring $15 \times 15 \mathrm{~cm}$ weighing 72 grams, it consists of a spring piston that slides freely on a rod within the body of instrument. The piston drives an independent sliding indicator along a slot marked with a scale graduated, low range from 50 to 350 litres per minute and high range from 60 to 800 litres per minute. The indicator records the maximum movement of the piston. The machine must be held horizontally with air vents uncovered [5]. The instrument may be cleaned easily in running water or in a detergent solution.

Peak expiratory flow rate is a dynamic lung function test and accepted index of lung function which is widely used in respiratory medicine. It is simple and easy procedure when it is compared to pulmonary function test. Peak flow rate primarily reflects large airway flow and depends on the voluntary effort and muscular strength of the patient. PEFR depends on airway resistance. The principle factor which determines PEFR is the degree to which the bronchial airways are patent or obstructed. In normal males the range of PEFR lies between $450-700 \mathrm{~L} / \mathrm{min}$. Normal females have a lower range between $300-500 \mathrm{~L} / \mathrm{min}$. The present study is to carry out and evaluate the diurnal variations in healthy young south indian females.

Peak Expiratory Flow Rate (PEFR) is recorded in Mini Wrights Peak Flow Meter and it is commonly used for screening: the individuals who are asthmatics and chronic airway obstruction. PEFR shows regular variation which follows a specific pattern in airway obstruction among healthy young adults. PEFR shows an hour to hour variations in all individuals.

Factors affecting Peak expiratory flow rate:

1. Anthropometric measurement: Standing height is the single best predictor of PEFR [6].

2. Age and Gender: Age has linear relationship with PEFR but gender has no significant relation with PEFR in children when height is considered. When only age is considered PEFR differs in both genders [7].

3. Nutrition: inverse relationship with PEFR [8].

4. Environmental effect: smoking and environmental tobacco smoke increases airway variability, thereby effect PEFR. Air pollution also has a significant impact on PEFR especially in children $[9,10]$.

5. Respiratory system: PEFR occurs early in expiration and is dependent on personal effort, large airway resistance. Chest wall deformity and respiratory infections can also cause a reduced PEFR.

PEFR has been suggested as a fair indicator of bronchial hyperresponsivness. Variability in the airway function during 24hours, observed as a characteristic diurnal variations in PEFR has been observed not only in asthmatics even it is observed in healthy individuals also [11]. Very few studies are done on healthy young adults and there is not clear demarcation of gender variation of PEFR variability. PEFR is known to show a circadian rhythm in healthy adults and its variability in patients with bronchial hyper reactivity. Circardian oscillations in the sympathetic activity may have impact on the airway smooth muscles. PEFR shows an regular variation that follows a specific pattern [12]. Adequate data are not available on the diurnal variation in normal individuals who are students in professional courses and living a sedentary lifestyle [12]. Measuring PEFR variability has often been promoted as a good alternative for challenge testing [13].

Lowest PEFR values were seen in the morning and highest values were notes in the noon and there was a fall in the night. Circardian changes occur in close temporal relation with body temperature, oxygen consumption and carbon di oxide production. Breathing is closely regulated by metabolic rate, which is influenced by multiple factors including activity and state of arousal, as well as hormonal and autonomic nervous system inputs. Circardian oscillations in the sympathetic activity may have impact on the airway smooth muscles. None of these variables could fully explain the diurnal pattern of ventilation. Few studies suggest that scheduling elective surgical procedures or extubating patients with very limited lung function can be performed in accordance with the diurnal pulmonary clock [12].

Clinical use of peak expiratory flow rate (PEFR)

Diurnal variation in PEFR is good indicator of circadian variation in bronchial responsiveness. PEFR record with a diurnal variation of $20 \%$ or more is a good clinical and occupational indicator of asthma [14].

Daily variability $=\underline{\text { Highest PEFR }- \text { Lowest PEFR x } 100}$ Highest PEFR

PEFR is a very useful tool for monitoring and self management of asthma and to diagnose and to treat occupational asthma [15]. PEFR is a highly sensitive and accurate index of airway obstruction. It can be used as a guideline of admission and discharge of asthma when PEFR value more than 60\% [16]. Peak flow measurement is sensitive indicator to measure the strength of muscles of respiration. Serial measurements of PEFR in Guillian Barre syndrome or progressive flaccid paralysis is clinically important to assess the need for ventilator support [17].

\section{MATERIALS AND METHODS}

This cross-sectional study was carried out among the students and faculties of allied health science in the Department of Pulmonology, Sri Ramachandra Medical College and Research institute. The study was 
accomplished between November 2018- March 2019. Based on a study done by Mridha et al., [1], Pre test mean and Post test mean was $407+/-25.4$ and 416+/25 respectively, with power of $80 \%$ and alpha error of $5 \%$, we took least PEFR values difference as a reference to calculate sample size of 60 Sixty healthy females. All the participants were almost having same routine life and sleep habits. Smokers were excluded from the study. The participants were healthy females in the age group of 18-25 yrs. A data sheet was provided to students to fill up for the selection of the participants in the study. The data sheet consisted of Name, Age, Gender, BMI (Height and Weight) were noted. Volunteers' with history of smoking, severe chest trauma, with obvious chest and spinal deformity with personal and family history of asthma, COPD and cardiorespiratory diseases were excluded from the study. Finally 60 participants were selected for this study.

All participants were explained about the study. The PEFR was recorded by Mini Wrights PEFR. Before the study started all the participants were given training for a day, PEFR technique was taught. They were instructed to record PEFR in erect posture, five times a day on [6 A.M, 10 A.M, 2 P.M, 6 P.M, 10 P.M.] in a single day. The best of three PEFR readings in a given time was taken for analysis to obtain a good reference data.

\section{Precautions Observed During the Manoeuvre}

- It was ensured that the participant was comfortable and relaxed.

- The apparatus was sterilized and cleaned properly.

- The participants was trained adequately to perform different manoeuvre.

- The participants was instructed to hold the instrument in a such a way that the hand did not obstruct the movement of the pointer.

- The pointer was kept at the lower most level.

\section{STASTICAL ANALYSIS}

Statistical analysis was done to observe the diurnal variation of PEFR, the maximum out of the five recordings were taken as the final value. These values at different time points were analyzed using repeated measures of ANOVA which shows diurnal variations were statistically significant.

Table-1: Mean and Standard Deviation

\begin{tabular}{|l|l|l|}
\hline Time & Mean (PEFR L/min) & Std. Deviation \\
\hline $6.00 \mathrm{am}$ & 313.00 & 56.817 \\
\hline $10.00 \mathrm{am}$ & 332.50 & 52.839 \\
\hline $2.00 \mathrm{pm}$ & 353.08 & 52.149 \\
\hline $6.00 \mathrm{pm}$ & 364.50 & 53.184 \\
\hline $10.00 \mathrm{pm}$ & 349.83 & 52.770 \\
\hline
\end{tabular}

Since the Sphericity not assumed, By GREENHOUSE GEISSER the difference between the means is satistically significant $F(4,129)=50.173$. $\mathrm{P}<0.001$.

A pair wise comparison using Bonferroni correction revealed that the difference between $6.00 \mathrm{am}$ and all the other time points was statistically significant. The difference between $10.00 \mathrm{am}$ as compared to $2 \mathrm{pm}$, $6 \mathrm{pm}$ and $10 \mathrm{pm}$ were statistically significant. There is no significant difference in the afternoon (2 P.M) and night (10P.M) PEFR values.

\section{CORRELATION OF PEFR WITH TIME}

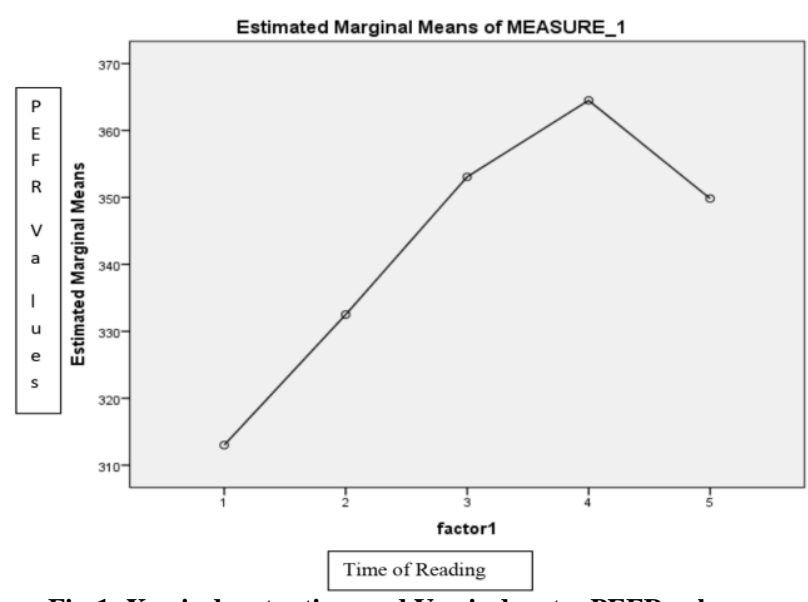

Fig-1: $\mathrm{X}$ axis denotes time and $\mathrm{Y}$ axis denotes PEFR values

\section{DISCUSSION}

This study was conducted in a hospital setting, but care was taken to include only healthy individuals, we deliberately excluded smokers from our study as smoking is known to increase diurnal variation in PEFR [12]. We used mini-Wright peak flow meters for this study and the subjects kept their own records. Self recording of PEFR has been earlier shown to be fairly reliable. It is of clear evidence that gender is a factor that affects PEFR and similar observation was seen in the study done by Jena SK et al., [19]. A study done by H.M Boezen et al., suggested that diurnal variation of PEFR is affected by age and elderly has higher variation [18]. However our study was distributed over a relatively narrow age range, it is therefore difficult to comment upon this observation. Our results showed PEFR Values were low in the morning, followed by progressive rise peaking in the afternoon and evening and a small fall at night time. Increase in BMI within physiological limits increases PEFR, but in obese or malnourished individuals, PEFR is likely to vary depending on possible co-morbid conditions. Highest PEFR is seen around the midpoint, as it has been suggested that rhythm in the plasma cortisol may be due to pulmonary clock. Ethnic differences in the normal range of spirometric values have been described. Geographic factors, exposure to environmental and occupational pollution, and socioeconomic status may 
influence interindividual variation. Therefore, it would be more appropriate for each region to have its own value [20].

\section{CONCLUSION}

Mean age of patients in this study was 20years with mean BMI of 21.65. This study concludes that there is significant difference between five groups. Comparing the PEFR readings there is a diurnal variation in healthy young females showing a overall dip in the morning PEFR at 6 A.M with mean of 313L/min with SD 56.817, peaking in the evening PEFR at 6 P.M with mean of $364 \mathrm{~L} / \mathrm{min}$ with SD 53.184 and eventually decreased in night PEFR at 10P.M with mean of $349.83 \mathrm{~L} / \mathrm{min}$ with SD 52.770 . But, there is no significant difference in the afternoon $(2$ P.M) and night (10-P.M). This study provided the reference data of diurnal variation of peak expiratory flow rate in healthy young females. Since, there is a variation in the peak expiratory flow rate recorded during different time points of the day; hence, to compare the PEFR between individuals it is advisable to record the PEFR at the same time point.

\section{REFERENCE}

1. Mridha, M. A., \& Ruhulamin, M. (2002). Peak expiratory fow rate in normal school children of Dhaka city, Bangladesh. Bangladesh $J$ child health, 26(3/4), 46-51.

2. Brown, L. A., \& Sly, R. M. (1980). Comparison of Mini-Wright and standard Wright peak flow meters. Annals of allergy, 45(2), 72-74.

3. Wright, B. M., \& McKerrow, C. B. (1959). Maximum forced expiratory flow rate as a measure of ventilatory capacity. British medical journal, 2(5159), 1041-1047.

4. Levin, E., \& Gold, M. I. (1981). The mini-Wright expiratory peak flow meter. Canadian Journal of Anesthesia/Journal canadien d'anesthésie, 28(3), 285-287.

5. Perks, W. H., Tams, I. P., Thompson, D. A., \& Prowse, K. (1979). An evaluation of the miniWright peak flow meter. Thorax, 34(1), 79-81.

6. Malik, S. K., Jindal, S. K., Banga, N., Sharda, P. K., \& Gupta, H. D. (1980). Peak expiratory flow rate of healthy north Indian teachers. The Indian journal of medical research, 71, 322-324

7. Carson, J. W., Hoey, H., \& Taylor, M. R. (1989). Growth and other factors affecting peak expiratory flow rate. Archives of disease in childhood, 64(1), 96-102.

8. Frischer, T., Kühr, J., Meinert, R., Karmaus, W., \& Urbanek, R. (1993). Influence of maternal smoking on variability of peak expiratory flow rate in school children. Chest, 104(4), 1133-1137.

9. Neas, L. M., Dockery, D. W., Koutrakis, P., Tollerud, D. J., \& Speizer, F. E. (1995). The association of ambient air pollution with twice daily peak expiratory flow rate measurements in children. American journal of epidemiology, 141(2), 111-122.

10. Pfaff, J. K., \& Morgan, W. J. (1994). Pulmonary function in infants and children. Pediatric Clinics of North America, 41(2), 401-424.

11. Ashfaq, S. H. A. H. B. A. Z., \& Saeed, M. U. N. I. Z. A. (2009). Diurnal Variation in Peak Expiratory Flow Rates of Healthy Young Adults. Pakistan Journal of Medical \& Health Sciences, 3(2), 125127.

12. Jayapal, J. (2014). A study of diurnal variation in peak expiratory flow rates in healthy adult female subjects in South India. CHRISMED Journal of Health and Research, 1(3), 184-186.

13. Gannon, P. F. G., Newton, D. T., Pantin, C. F. A., $\&$ Burge, P. S. (1998). Effect of the number of peak expiratory flow readings per day on the estimation of diurnal variation. Thorax, 53(9), 790-792.

14. Hassan M. R., Hossain, M. A., Mahmud, A. M., Kabir, A., Ruhulamin, M., \& Bennoor, K. S. (1999). National asthma guidelines for medical practioners. Asthma Assocation of Bangladesh. IDCH campus, Mohakhali, Dhaka; 73-94.

15. Andrew, H. L., Joseph, D., \& Donald, Y. M. L. (2004). Allergic disorder, Childhood asthma, PEF monitoring In: Behrman, R. E., Kliegman, R. M., Jenson, H. B. (editors), Nelson Textbook of Pediatrics. 17th edition, 764-765.USA, WB Saunders Co.

16. Brown, J. K., \& Minns, R. A. (1998). Disorder of the central nervous system, Diseases of the peripheral nervous system In: Campbel, A. G. M., \& McIntosh, $\mathrm{N}$ (editors), Forfar and Arneil's Textbook of Pediatrics, 5th edn, 725-726. London, Churchill Livingstone.

17. Lebowitz, M. D., Knudson, R. J., Robertson, G., \& Burrows, B. (1982). Significance of intraindividual changes in maximum expiratory flow volume and peak expiratory flow measurements. Chest, 81(5), 566-570.

18. Boezen, H. M., Schouten, J. P., Postma, D. S., \& Rijcken, B. (1994). Distribution of peak expiratory flow variability by age, gender and smoking habits in a random population sample aged 20-70 yrs. European Respiratory Journal, 7(10), 18141820.

19. Jena, S. K., Mohanty, A., Mania, R. N., \& Pal, A. (2017). Diurnal variation of peak expiratory flow rate in healthy young adults: A gender-based study. Journal of Medical Society, 31(2), 104-108.

20. Nayak, P. K., Satpathy, S., Manjareeka, M., Samanta, P., Mishra, J., \& Pradhan, B. B. (2016). Prediction models for peak expiratory flow rate in Indian population aged 18-25 years. National Journal of Physiology, Pharmacy and Pharmacology, 6(3), 200-204. 